\title{
Potential of trans fats policies to reduce socioeconomic inequalities in mortality from coronary heart disease in England: cost effectiveness modelling study
}

\author{
Kirk Allen, ${ }^{1,2}$ Jonathan Pearson-Stuttard, ${ }^{3}$ William Hooton, ${ }^{4}$ Peter Diggle, ${ }^{1}$ Simon Capewell, ${ }^{2}$ \\ Martin O'Flaherty ${ }^{2}$
}

${ }^{1}$ Lancaster Medical School,

Lancaster University, Lancaster

LA1 4YW, UK

2Department of Public Health and Policy, Liverpool University, Liverpool L69 3GB, UK

${ }^{3}$ Division of Medical Sciences, University of Oxford, Oxford OX3 9DU, UK

4Pembroke College Alumni, University of Oxford, Oxford OX1 1DW, UK

Correspondence to:

KAllen allenk@liverpool.ac.uk Additional material is published online only. To view please visit the journal online (http://dx.doi. org/10.1136/bmj.h4583)

Cite this as: $B M J$ 2015;351:h4583 doi: 10.1136/bmj.h4583

Accepted: 14 August 2015

\section{ABSTRACT}

OBJECTIVES

To determine health and equity benefits and cost effectiveness of policies to reduce or eliminate trans fatty acids from processed foods, compared with consumption remaining at most recent levels in England.

\section{DESIGN}

Epidemiological modelling study.

\section{SETTING}

Data from National Diet and Nutrition Survey, Low Income Diet and Nutrition Survey, Office of National Statistics, and health economic data from other published studies.

\section{PARTICIPANTS}

Adults aged $\geq 25$, stratified by fifths of socioeconomic circumstance.

\section{INTERVENTIONS}

Total ban on trans fatty acids in processed foods; improved labelling of trans fatty acids; bans on trans fatty acids in restaurants and takeaways.

MAIN OUTCOME MEASURES

Deaths from coronary heart disease prevented or postponed; life years gained; quality adjusted life

\section{WHAT IS ALREADY KNOWN ON THIS TOPIC}

Industrial trans fatty acids (TFA) are commonly added to processed foods to cheaply improve shelf life and palatability. Their removal from processed foods in the UK is part of the Department of Health's responsibility deal, and other countries have used total bans, labelling, and restaurant bans to achieve bigger reductions in consumption

Trans fatty acids increase risk of mortality from coronary heart disease by increasing LDL cholesterol, decreasing HDL cholesterol, and causing systemic inflammation as well as endothelial dysfunction

Mortality from coronary heart disease and consumption of trans fatty acids are higher among disadvantaged socioeconomic groups

\section{WHAT THIS STUDY ADDS}

A total ban on industrial trans fatty acids in processed foods in England might potentially prevent or postpone about 7200 deaths from coronary heart disease $(2.6 \%)$ in $2015-20$ and reduce inequality in mortality from coronary heart disease by about 3000 deaths (15\%)

A total ban would have the greatest net cost savings of $£ 264 \mathrm{~m}$ if reformulation occurs as a normal part of the business cycle or $f 64 \mathrm{~m}$ if substantial reformulation costs are incurred outside the normal cycle

Improved labelling of trans fatty acids or bans in restaurants would be at best half as effective in terms of reducing both mortality and inequalities. These policies could still be cost saving from a societal perspective because of the potentially large reductions in incidence of and mortality from coronary heart disease

years gained. Policy costs to government and industry; policy savings from reductions in direct healthcare, informal care, and productivity loss.

\section{RESULTS}

A total ban on trans fatty acids in processed foods might prevent or postpone about 7200 deaths (2.6\%) from coronary heart disease from 2015-20 and reduce inequality in mortality from coronary heart disease by about 3000 deaths (15\%). Policies to improve labelling or simply remove trans fatty acids from restaurants/ fast food could save between 1800 (0.7\%) and 3500 (1.3\%) deaths from coronary heart disease and reduce inequalities by 600 (3\%) to 1500 (7\%) deaths, thus making them at best half as effective. A total ban would have the greatest net cost savings of about $£ 265 \mathrm{~m}(€ 361 \mathrm{~m}, \$ 415 \mathrm{~m})$ excluding reformulation costs, or $f 64 \mathrm{~m}$ if substantial reformulation costs are incurred outside the normal cycle.

\section{CONCLUSIONS}

A regulatory policy to eliminate trans fatty acids from processed foods in England would be the most effective and equitable policy option. Intermediate policies would also be beneficial. Simply continuing to rely on industry to voluntary reformulate products, however, could have negative health and economic outcomes.

\section{Introduction}

Cardiovascular diseases are the most common cause of mortality in the United Kingdom, with around 180000 deaths in 2010 and economic costs of €19bn (€26bn, $\$ 30 b n$ ) in 2009. ${ }^{1}$ Coronary heart disease is the most common type of cardiovascular disease, causing some 80000 deaths in 2010. Premature mortality from coronary heart disease is substantially higher among the most disadvantaged socioeconomic groups, ${ }^{2}$ and this inequality might increase in the future. ${ }^{3}$

Trans fatty acids are unsaturated fatty acids with at least one double bond in a trans position. They are produced naturally in small quantities in the stomachs of ruminants (such as cows and sheep) but are more commonly found in the diet from partially hydrogenated vegetable oils in processed foods. Trans fatty acids are desirable to the food industry because they allow longer shelf life, thermodynamic stability, and enhanced palatability. They increase low density lipoprotein cholesterol concentrations, decrease high density lipoprotein cholesterol concentrations, and can also cause systemic inflammation as well as endothelial dysfunction. ${ }^{4}$ A meta-analysis of pooled prospective studies found that for every $2 \%$ of total energy ( $\% \mathrm{E}$ ) that comes 
from trans fatty acids, there is a $23 \%$ increase (95\% confidence interval $11 \%$ to $37 \%$ ) in incidence of coronary heart disease. ${ }^{4}$ Higher intake is also associated with increased all cause mortality. ${ }^{5}$ This makes trans fatty acids more dangerous on a per gram basis than other types of fat.

Elimination of trans fatty acids from the UK diet is a key element of a suite of dietary policies that could reduce mortality from coronary heart disease in the UK. ${ }^{6}$ Elimination is recommended by the UK Faculty of Public Health ${ }^{7}$ and by the World Health Organization, which includes elimination in its global strategy on diet, physical activity and health. ${ }^{8}$ Currently in the UK, elimination of trans fatty acids is a component of the Department of Health's “public health responsibility deal," 9 which simply advocates voluntary reformulation. Internationally, however, several types of public health policies have been enacted to reduce consumption of trans fatty acids: ${ }^{10}$ total bans, mandatory labelling, restaurant bans, and voluntary reformulation. We evaluated three options for further restricting consumption in England: a ban of trans fatty acids in processed foods, improved labelling of trans fatty acids, and a restaurant ban.

\section{Methods}

For policies aimed at reducing consumption, we calculated health benefits and cost outcomes for 2015-20 in England only. We restricted analysis to England because it is then feasible to easily link a socioeconomic indicator to mortality from coronary heart disease and incidence, where coronary heart disease is defined by ICD (international classifications of diseases) codes I20-I25. We applied methods originally incorporated into the previously validated IMPACT model, which explained between $80 \%$ and $95 \%$ of the decline in mortality from coronary heart disease from 2000 to 2007 for each socioeconomic circumstance group in England (IMPACT-SEC model) ${ }^{11}$ and recently extended into a trans fat model. ${ }^{12}$ The methods have been used to predict improvements in mortality from coronary heart disease that could result from improvements in other dietary and lifestyle risk factors. ${ }^{613}$ Briefly, IMPACT-SEC calculates the changes in numbers of patients with coronary heart disease and mortality between two time points attributable to changes in risk factors and treatments. In our analysis, the risk factor was consumption of trans fatty acids. Analyses were stratified by age, sex, and socioeconomic status. Age was categorised in 10 year bands starting at 25-34 and included an open ended final group of $\geq 85$. Socioeconomic status was summarised by fifths of the index of multiple deprivation (IMDQ, where IMDQ1 is most affluent and IMDQ5 is most disadvantaged). ${ }^{14}$ This index aggregates seven domains of deprivation (income, employment, health, education, crime, access to services, living environment), each of which is composed of around five indicators. It is an area based measure, and each small area has around 1500 people. Fifths are formed to have equal numbers of areas; because the populations per area are roughly constant, the popula- tions of the fifths are nearly equal as well. More details of each step in the calculations are outlined the appendix.

\section{Consumption of trans fatty acids in UK}

We determined intake of trans fatty acids from the most recent National Diet and Nutrition Survey, ${ }^{15}$ a representative sample of UK households where selected individuals complete food diaries. Based on the average grams per day of trans fatty acids and the average kcal per day, we used a value of $9 \mathrm{kcal}$ per gram to convert grams of trans fatty acids to a percent energy (\%E) basis. The result is that consumption was about $0.7 \% \mathrm{E}$ in 2008-09 to 2011-12. We treated this as the average consumption for IMDQ3 in England. An early release of data covering 2008-09 to 2009-10 indicated slightly higher consumption $(0.8 \% \mathrm{E})$. Lower income groups have higher consumption, of about $1.3 \% \mathrm{E}$ based on data released in 2007. ${ }^{16}$ We treated this as the consumption for the most disadvantaged fifth for IMDQ5 in England, with a slight decrease to $1.2 \% \mathrm{E}$ to account for differences in the time periods.

The National Diet and Nutrition Survey estimates which food types contribute trans fatty acids, with the primary sources of industrial trans fatty acids being cereal products, margarines, potato chips, confectionary, and other snacks. We estimated a level of trans fatty acids from ruminant sources to be at most $0.4 \% \mathrm{E}$. The way in which data are reported (such as "pork and dishes") implies that some of this might still be industrial trans fatty acids (such as the breading on meat in microwavable meals).

Because there are no data for consumption of trans fatty acids for more affluent socioeconomic groups, we assumed that IMDQ1 had a value of $0.5 \% \mathrm{E}$, implying that nearly all of their consumption is from ruminant sources. The total consumption and ruminant consumption for all IMDQs are summarised in table 3, and details from the dietary surveys are in table A and B in the appendix, in which we also show the key results if consumption is equal across IMDQs.

\section{Policy options modelled}

We modelled three policy options that could reduce consumption of trans fatty acids in England, based on an international policy review. ${ }^{10}$ Our comparator was that future consumption would remain constant, therefore not effecting underlying trends in mortality from coronary heart disease.

\section{Total ban in processed foods}

Beginning in 2004, Denmark required that oils and fats used in processed foods contain less than $2 \%$ trans fatty acids. Because this was at the level of ingredients, rather than in the final product, consumption of industrial trans fatty acids was reduced to essentially zero. ${ }^{17}$ This reduction made an important contribution to declines in coronary heart disease in Denmark. ${ }^{18}$ Bans on trans fatty acids in Austria and Switzerland began in 2009, ${ }^{19}$ Iceland in 2010, and Hungary and Norway in 2014. ${ }^{20}$ The United States has initiated the process to ban trans fatty acids in processed foods. ${ }^{21}$ 
We evaluated the effect of a total ban in processed foods in England by lowering consumption to the baseline for ruminant trans fatty acids $(0.4 \% \mathrm{E}$ as outlined above). For example, this would mean reducing intake from $0.7 \% \mathrm{E}$ to $0.4 \% \mathrm{E}$, a reduction of $0.3 \% \mathrm{E}$.

\section{Labelling}

In the US, the Food and Drug Administration requires that trans fatty acids be listed on food labels. Products with less than $0.5 \mathrm{~g}$ per serving can be labelled as having "zero" trans fatty acids, which is potentially problematic for customers who eat many items with less than $0.5 \mathrm{~g}$ per serving. ${ }^{22}$ The rule was announced in 2003 and took effect in 2008.

In a market analysis in the US, trans fatty acid content was reduced in $66 \%$ of processed foods between 2007 and 2011. The mean content declined by $49 \%$ between 2007 and 2011 because of voluntary reformulation on the part of industry. The decline was greatest in the first year (30\% in 2007-08.) $)^{23}$

We evaluated two labelling scenarios for England. We modelled a $49 \%$ reduction in trans fatty acids in processed foods based on the experience in the US. ${ }^{23}$ To evaluate potential socioeconomic gradients, we assumed that IMDQ1 would have the full benefit and IMDQ5 would have only half that reduction (24.5\%) based on expert opinion of socioeconomically differentiated response to salt labelling. ${ }^{24}$ Other IMDQs were linearly interpolated between IMDQ1 and IMDQ5. To estimate the maximum effect that labelling might have, we assumed that the maximum response of $49 \%$ reduction in trans fatty acids in processed foods would occur in all IMDQs.

Partial ban: restaurant and takeaway (fast food) ban In July 2008, New York City implemented a policy that required restaurant items to contain a maximum of $0.5 \mathrm{~g}$ trans fatty acids per serving. This was initially a voluntary ban but, because of poor compliance, became mandatory after 12 months. In a before and after analysis of major chain fast food restaurants, there was an 83\% decline (more than $2 \mathrm{~g}$ ) per serving. The corresponding increase in saturated fat per serving was much smaller $(0.5 \mathrm{~g}) .{ }^{25}$ As with labelling, quantities less than $0.5 \mathrm{~g}$ per serving could still lead to non-trivial accumulations, especially among heavy consumers.

We evaluated two restaurant scenarios for England. There are no data from the UK about consumption of trans fatty acids in restaurant food. As a proxy, we used data on food expenditure away from home (excluding alcohol), ${ }^{26}$ assuming that consumption away from home is proportional to expenditure away from home. Data are given by 10th of household income. We converted this to IMDQ (for example, the two lowest 10ths of income were assigned to IMDQ5). With these assumptions, people in IMDQ1 consume $40 \%$ of trans fatty acids outside the home, with an approximately linear decline to $22 \%$ for IMDQ5. This scenario reflects restaurant food. Details are in table $\mathrm{C}$ in the appendix. We ran a second scenario for takeaway/fast food. Expenditure data might be a poor proxy for consumption of trans fatty acids because fast food consumption is likely to be higher in the most disadvantaged groups. This scenario tested the reverse, whereby people in IMDQ5 consume $40 \%$ of trans fatty acids away from home, declining to $22 \%$ for IMDQ1.

\section{Health outcomes}

We calculated the reduction in incidence of coronary heart disease based on the meta-analysis ${ }^{4}$ relating consumption of trans fatty acids to incidence of coronary heart disease (23\% (95\% confidence interval $11 \%$ to $37 \%$ ) reduction per $2 \% \mathrm{E}$ decrease in trans fatty acids). We assumed that mortality from coronary heart disease would change by the same amount and that reducing trans fatty acids would have no effect on case fatality. To create age specific values for the benefit between trans fatty acids and mortality from coronary heart disease, we assumed that the association would resemble that observed for cholesterol and coronary heart disease. ${ }^{27}$ Details can be found in table $\mathrm{D}$ in the appendix.

A projection of mortality from coronary heart disease for England for 2015-20 was estimated using an ageperiod-cohort model. ${ }^{3}$ This model extrapolated past trends in age specific mortality from coronary heart disease by sex and IMDQ.

We used reductions in mortality from coronary heart disease to calculate deaths prevented or postponed for each year 2015-20. For example, if mortality was reduced from 50 per 100000 to 45 per 100000 , then there would be five deaths prevented or postponed per 100000 . These rates were converted to absolute numbers by using population projections from UK's Office for National Statistics (ONS). We further stratified these into IMDQ using the age-sex structure from 2013 (described in the appendix).

Deaths prevented or postponed were translated to life years gained by partitioning them in 2020 into three disease states: diagnosed coronary heart disease, undiagnosed coronary heart disease, and no coronary heart disease. The percentages attributed to each disease state were $26 \%, 26 \%$, and $48 \%$, respectively, based on the contribution of treatments to declines in mortality from coronary heart disease for the IMPACT-SEC model. ${ }^{11}$ Each disease state has its own median survival stratified by age and sex (table $\mathrm{E}$ in the appendix). The deaths prevented or postponed for each disease state were multiplied by the median survival for each disease state and then summed to yield the total life years gained. Smolina and colleagues describe the method in more detail. ${ }^{28}$ A social gradient in median survival by IMDQ for undiagnosed coronary heart disease and no coronary heart disease was applied based on recent analyses from the Office for National Statistics. ${ }^{29}$ We assumed no differences in median survival for diagnosed coronary heart disease because treatment uptake has been shown to be equitable. ${ }^{30}$

To further convert life years gained to quality adjusted life years (QALYs), we used health state utility values $^{31}$ for each of the three subgroups of coronary heart disease (acute myocardial infarction, unstable angina, and heart failure). The proportions of incident 
cases of total coronary heart disease in each subgroup were based on data from British Heart Foundation. ${ }^{1}$ For each subgroup, we multiplied the health state utility value by the life years gained, weighted by the incidence proportion. Table 1 shows these values.

\section{Inequality in health outcomes}

We used the slope index ${ }^{32}$ to quantify absolute inequality in deaths prevented across IMDQ. Based on a simple linear regression of the number of deaths by IMDQ, the slope index is the fitted difference between IMDQ5 and IMDQ1. This takes into account variation across all IMDQs, which can be slightly different than the simple difference between IMDQ5 and IMDQ1. We calculated the slope index at baseline (without trans fatty acids policies) and with each policy option, and we report the change in the index. For example, if the baseline slope index of deaths prevented or postponed is 10000 and the slope index with a trans fatty acids policy is 8000 , then the change in slope index is -2000 (an absolute inequality reduction of 2000 deaths from coronary heart disease). An illustrative example is shown in the appendix.

\section{Economic modelling}

The cost utility analysis considered the societal costs, including costs to the state and industry, and savings in costs for healthcare and wider economy. The state costs included a one-off cost associated with passing legislation and an ongoing cost of policy monitoring. The industry costs included a one-off cost to industry of product re-formulation as well as an ongoing "lost profitability" cost. The wider economy benefits included the saving from averted productivity loss and saved informal care costs. All costs and benefits were modelled over the five year period 2015-20 for each of the policy scenarios outlined above.

\section{State costs}

Government costs because of legislation (a one-time cost of $£ 5 \mathrm{~m}$ in 2015) were estimated from the salt policy analysis $^{33}$ to include such activities as consultancy fees and implementation. Monitoring costs (annual cost of $£ 2.4 \mathrm{~m}$ ) have been reported by the Food Standards Agency $^{34}$ to capture activities related to checks on labelling and updates to collection of data from dietary surveys.

\begin{tabular}{|c|c|c|c|}
\hline CHD subtype & $\begin{array}{l}\text { Health state } \\
\text { utility values }\end{array}$ & $\begin{array}{l}\text { Cost per } \\
\text { patient }\end{array}$ & Proportion \\
\hline $\begin{array}{l}\text { Acute myocardial } \\
\text { infarction }\end{array}$ & 0.88 & $£ 2880$ & 0.69 \\
\hline Unstable angina & 0.80 & $£ 2638$ & 0.14 \\
\hline Heart failure & 0.71 & $£ 2974$ & 0.17 \\
\hline \multicolumn{4}{|c|}{$\begin{array}{l}\text { *1 represents perfect health, } 0 \text { represents death, and intermediate } \\
\text { values signify that life years lived after CHD incidence are hampered by } \\
\text { poor health. }{ }^{32} \text { QALY per life year gained is average of health state utility } \\
\text { values weighted by proportions, which works out to } 0.84 \text {. }\end{array}$} \\
\hline
\end{tabular}

\section{Industry costs}

Worst case industry costs for reformulation are assumed to be $€ 200 \mathrm{~m}$ ( 8000 products at $€ 25000$ per product). ${ }^{3435}$ The best case would be zero if reformulation is already built into the business model and occurs about every 18-36 months. ${ }^{36}$ For policies that lead to partial reformulation, the worst case scenario was assumed to be proportional to the average reduction in trans fatty acids (for example, an average 50\% reduction would have worst case costs of $50 \%$ of $£ 200 \mathrm{~m}$-that is, $£ 100 \mathrm{~m})$. For labelling, we assumed a baseline of $€ 20 \mathrm{~m}$ from changes in packaging and loss through disuse of existing packaging, ${ }^{33}$ with reformulation then added on top. All policies would also have ongoing (annual) costs to industry estimated at about $€ 2 \mathrm{~m}$.

\section{Healthcare costs and savings}

We created a counterfactual for the number of patients with coronary heart disease in three major categories (acute myocardial infarction, unstable angina, heart failure) using a baseline of numbers of patients in 2007.11 Baselines for future years were estimated by assuming that numbers (incidence) would continue to decline by 5\% annually, as observed between 2002 and 2010. ${ }^{1}$ Then, based on the reduction in trans fatty acids for each policy option, we calculated that incidence would decline using the trans fatty acids meta-analysis. ${ }^{4}$ Direct healthcare costs per patient group were reported by the Personal Social Services Research Unit ${ }^{37}$ (table 1).

\section{Informal care savings}

Informal care savings per patient were calculated from the total informal care expenses in 2009 divided by the total number of patients with coronary heart disease in $2009^{1}$ ( $£ 1.4 \mathrm{bn} / 126000$ patients $=£ 12200$ per patient in 2009). Informal care represents the opportunity cost that carers incur by not participating in paid work, based on those caring for patients with coronary heart disease who were the most severely hampered by the disease. ${ }^{38}$

\section{Productivity loss averted}

Productivity loss averted was calculated with the frictional unemployment savings method, representing the time for an ill employee to be replaced by a new employee as opposed to the time away from work lost by the ill employee. Frictional unemployment is the product of the average time to replace an employee, the average hours worked a day, and the average hourly wage. ${ }^{39}$ For 90 days at eight hours a day this works out at about $€ 9100$ per patient with coronary heart disease. Frictional unemployment is applied only to the working age population (age $<65$ ).

\section{Cost effectiveness}

We calculated net costs of each modelled policy at three levels. Firstly, we summed all cost savings (healthcare plus informal care plus averted productivity loss; see table 6). Next, we added on the fixed costs common to all policies (costs to government plus ongoing expenses 


\begin{tabular}{|c|c|}
\hline Model parameter & Sensitivity analysis \\
\hline TFA link to incidence of CHD & Normal distribution of meta-analysis coefficient (23\%, 95\% Cl 11\% to 37\%) \\
\hline CHD mortality & $\begin{array}{l}\text { Normal distribution of logit of predicted rates based on upper and lower confidence intervals } \\
\text { from model output }^{3}\end{array}$ \\
\hline No with CHD (incidence) & $\begin{array}{l}\text { Annual percent decline in patient numbers could vary from } 0 \% \text { to } 10 \% \text {. PERT distribution was } \\
\text { used with best estimate of } 5 \% \text { decline }\end{array}$ \\
\hline Direct health costs per patient & Assume PERT distribution with $20 \%$ variability around reported values (table 1) \\
\hline Median survival & Assume PERT distribution with $20 \%$ variability around medians \\
\hline
\end{tabular}

to industry; see table 7), representing the optimistic estimate of the net costs of each policy. Finally, we added on the worst case costs to industry, representing the pessimistic estimate of net costs of each policy (see table 7).

\section{Inflation and discounting}

Economic parameters from past data (for example, cost per patient from 2011) were inflated to 2015 by assuming $3 \%$ inflation annually, which is about the average annual increase in the consumer price index since 2008. 40 Costs and benefits for beyond 2015 were discounted back to 2015 at a rate of $3.5 \%$ annually according to NICE guidelines. ${ }^{31}$ QALY were discounted back to 2015 with this same rate.

\section{Sensitivity analysis}

We used probabilistic sensitivity analysis to estimate the effect of uncertainty in key parameters. For each policy option, we performed 1000 runs of the full model in $\mathrm{R}$ version 3.0.1.41 The key parameters that we included were consumption of trans fatty acids, link to mortality from coronary heart disease, mortality from coronary heart disease, numbers of patients with coronary heart disease (incidence), and, for labelling, the strength of the gradient of socioeconomic class (table 2). We also present in the appendix a one way sensitivity analysis of the gradient socioeconomic class in consumption of trans fatty acids.

\section{Patient involvement}

There was no patient involvement in this study.

\section{Results}

Reduction in consumption of industrial trans fatty acids

A full ban on industrial trans fatty acids in processed foods could halve the amount of trans fatty acids in the English diet, resulting in a new average of around $0.4 \%$ of energy from ruminant trans fatty acids (meat, dairy, etc). Improved labelling and associated voluntary reformulation could be at best half as effective as a total ban. If labelling also has a behavioural component that favours the more affluent (IMDQ1), then the most disadvantaged would see little decline in consumption of trans fatty acids (a decline of $0.20 \%$ energy for IMDQ5).
Bans on trans fatty acids in restaurants would favour the most affluent based on our proxy of food expenditure. The effect would be about $40 \%$ of that of the full ban for the most affluent and about $20 \%$ for the most disadvantaged. Alternatively, if trans fatty acids are mostly consumed in fast food outlets used by the most disadvantaged, they would proportionally benefit more but still fall well short of the potential of a full ban. Table 3 provides detailed results for all policies.

\section{Health benefits of reduction in trans fatty acids}

We translated the reduction in trans fatty acids to a reduction in deaths from coronary heart disease over the period 2015-20 (table 4). A full ban would reduce total coronary heart disease deaths by about $2.6 \%$ (7200 deaths, 95\% confidence interval 3200 to 12500 deaths), and the disadvantaged would benefit more because of their higher mortality from coronary heart disease and greater reduction in intake of trans fatty acids. Inequality in deaths from coronary heart disease would be reduced by about 15\% (3000 deaths, 1300 to 5200 deaths). Labelling with no social gradient would be about half as effective across all groups. If response to labelling has a social gradient, as seems plausible, the reduction would be around a third compared with the total ban. In the fast food scenario, where we assumed that consumption of trans fatty acids outside the home is higher in the poorest fifth, the effect would be slightly less than that for labelling and around a third as effective as the total ban. A restaurant ban that favours the more affluent would be about a quarter as effective as the total ban.

We translated the reduction in mortality in the year 2020 into QALYs (table 5). Again, the total ban would be especially beneficial for the most disadvantaged (IMDQ5) because the differences in mortality from coronary heart disease across IMDQs are greater at younger ages, when deaths avoided save more life years. As before, the other policy scenarios would be about a third to a half as effective as the total ban.

\section{Economic benefits and costs}

Table 6 shows the potential direct healthcare savings, averted productivity loss, and informal care savings for 2015-20. The total ban would save about $£ 42 \mathrm{~m}$ in direct health expenses, with nearly half of that (£19m) attrib- 


\begin{tabular}{|c|c|c|c|c|c|c|c|}
\hline \multirow[b]{2}{*}{ IMDQ } & \multirow[b]{2}{*}{ Total consumption* } & \multirow[b]{2}{*}{$\begin{array}{l}\text { Ruminant } \\
\text { sourcest }\end{array}$} & \multicolumn{5}{|l|}{ Reductions } \\
\hline & & & Total bansł & $\begin{array}{l}\text { Label (no SEC } \\
\text { gradient)§ }\end{array}$ & Fast foodๆ & $\begin{array}{l}\text { Label (SEC } \\
\text { gradient)** }\end{array}$ & Restaurantt† \\
\hline 1 & 0.50 (0.46 to 0.54$)$ & 0.40 & 0.10 (0.06 to 0.14$)$ & 0.05 (0.03 to 0.07$)$ & 0.02 (0.01 to 0.03$)$ & 0.05 (0.04 to 0.06$)$ & $0.04(0.02$ to 0.06$)$ \\
\hline 2 & 0.60 (0.56 to 0.64$)$ & 0.40 & 0.20 (0.16 to 0.24$)$ & 0.10 (0.08 to 0.12$)$ & 0.05 (0.04 to 0.06$)$ & 0.09 (0.08 to 0.10$)$ & 0.07 (0.05 to 0.09$)$ \\
\hline 3 & 0.70 (0.66 to 0.74$)$ & 0.40 & 0.30 (0.26 to 0.34$)$ & 0.15 (0.13 to 0.17$)$ & 0.10 (0.09 to 0.11$)$ & 0.11 (0.10 to 0.12$)$ & 0.10 (0.09 to 0.11$)$ \\
\hline 4 & 0.95 (0.91 to 0.99$)$ & 0.40 & 0.55 (0.51 to 0.59 ) & $0.27(0.25$ to 0.29$)$ & 0.19 (0.17 to 0.21$)$ & 0.17 (0.15 to 0.19$)$ & 0.15 (0.14 to 0.16$)$ \\
\hline 5 & 1.20 (1.16 to 1.24$)$ & 0.40 & 0.80 (0.76 to 0.84$)$ & 0.39 (0.37 to 0.41$)$ & $0.32(0.30$ to 0.34$)$ & $0.20(0.18$ to 0.22$)$ & 0.18 (0.17 to 0.19$)$ \\
\hline Average & 0.79 (0.75 to 0.83$)$ & 0.40 & 0.39 (0.35 to 0.43$)$ & 0.19 (0.17 to 0.21$)$ & 0.14 (0.12 to 0.16$)$ & 0.12 (0.10 to 0.14$)$ & 0.11 (0.10 to 0.12 ) \\
\hline $\begin{array}{l}\text { *Estimate } \\
\text { †Consump } \\
\text { †Eliminate } \\
\text { SReduce b } \\
\text { IReverse I } \\
\text { **IMDQ1 } \\
\text { †+Consum }\end{array}$ & $\begin{array}{l}\text { dietary surveys. }{ }^{15} 16 \\
\text { rom ruminant sources. }{ }^{15} \\
\text { ans fatty acids from proc } \\
\% \text { of total ban amount for } \\
\text { gradient of expenditure } \\
\text { aximum label effect ( } 49 \% \\
\text { away from home proport }\end{array}$ & $\begin{array}{l}\text { ed foods-that } \\
\text { IMDQ.23 } \\
\text { ay from home ( } \\
\text { inear down to }\end{array}$ & $\begin{array}{l}\text { uce to } 0.4 \% \text {. } \\
\text { IMDQ5)tt. } \\
\text { at } 50 \%{ }^{24} \text { of tha }\end{array}$ & $\%=24.5 \%)$. & & & \\
\hline
\end{tabular}

utable to the most disadvantaged fifth (IMDQ5). As with QALYs, the most disadvantaged would stand to gain proportionally more in averted productivity loss because the incidence of coronary heart disease is higher among the most disadvantaged at younger ages compared with the most affluent. The informal care savings are the largest component of these savings, representing about £196m savings from 2015 to 2020.

The costs to government would amount to about $£ 5 \mathrm{~m}$ for legislation and some $£ 16.6 \mathrm{~m}$ for annual monitoring, a sum of about $€ 21.6 \mathrm{~m}$ (table 7 ). Ongoing expenses to industry would amount to about $£ 11 \mathrm{~m}$. The sum of these costs, which are common to all policy options, is about $€ 32.6 \mathrm{~m}$. If industry reformulation costs are zero, this $£ 32.6 \mathrm{~m}$ would be the cost for each policy, which is our best case scenario. If industry incurred substantial reformulation costs, the worst case costs might lie between $\mathrm{f} 48 \mathrm{~m}$ and $\mathrm{£} 200 \mathrm{~m}$, according to the proportion of the total product line that required reformulation (table 3 shows percent reductions in consumption of trans fatty acids).

\section{Cost effectiveness of policy options}

The sum of all savings for the total ban would be about $£ 297 \mathrm{~m}$ (95\% confidence interval £131m to £466m), while for other policies the best estimates would lie in the range of $€ 80-147 \mathrm{~m}$ (fig 1 ). In the optimistic scenario, where the only costs would be to government and for ongoing expenses to industry, the costs might amount to $€ 33 \mathrm{~m}$ (table 7 ). The net costs would be a savings of $£ 264 \mathrm{~m}$ (£98m to $£ 433 \mathrm{~m}$ ) for the total ban or in the range $£ 48 \mathrm{~m}$ to $£ 115 \mathrm{~m}$ for other policies (table 7).

In the pessimistic scenario, where industry incurs substantial reformulation costs outside the normal business cycle, the costs might amount to a total of $£ 233 \mathrm{~m}$ for the total ban and between $£ 80 \mathrm{~m}$ and $£ 126 \mathrm{~m}$ for the other policy options. The net costs for the total ban would be savings of about $€ 64 \mathrm{~m}$ ( $95 \%$ confidence interval $-£ 102 m$ to $£ 233 m$ ), while for other policies the net costs would save in the range of $€ 0-£ 22 \mathrm{~m}$.

Figure 2 summarises the net costs and the reduction in absolute inequality of coronary heart disease mortality for each policy option. The additional benefits to the most disadvantaged group are evident in the large reduction in absolute inequality (reduction of 3000 coronary heart disease deaths). Combined with table 4, we can conclude that the larger reductions in incidence of coronary heart disease for IMDQ4 and IMDQ5 are the primary cause of cost saving.

\section{Discussion}

Policies to reduce or eliminate industrial trans fatty acids could powerfully improve coronary heart disease mortality, incidence, and inequalities in England. A total ban might reduce mortality from coronary heart disease for 2015-20 by around 2.6\%, representing

\begin{tabular}{|c|c|c|c|c|c|c|}
\hline \multirow[b]{2}{*}{ IMDQ } & \multirow[b]{2}{*}{ Baseline } & \multicolumn{5}{|l|}{ Reductions } \\
\hline & & Total ban & Label (no SEC gradient) & Fast food & Label (SEC gradient) & Restaurant \\
\hline 1 & 43000 & 300 (100 to 400 ); $0.7 \%$ & 100 (100 to 200$) ; 0.2 \%$ & 100 (0 to 100$) ; 0.2 \%$ & 100 (100 to 200$) ; 0.2 \%$ & 100 (0 to 200 ); $0.2 \%$ \\
\hline 2 & 50000 & 600 (300 to 1100$) ; 1.2 \%$ & 300 (100 to 500$) ; 0.6 \%$ & 200 (100 to 300 ); $0.4 \%$ & 300 (100 to 400 ); $0.6 \%$ & 200 (100 to 400$) ; 0.4 \%$ \\
\hline 3 & 57000 & 1000 (500 to 1800$) ; 1.8 \%$ & 500 (200 to 900 ); $0.9 \%$ & 300 (200 to 600$) ; 0.5 \%$ & 400 (200 to 700 ); $0.7 \%$ & 300 (100 to 600$) ; 0.5 \%$ \\
\hline 4 & 59000 & 2000 (900 to 3600); $3.4 \%$ & 1000 (400 to 1800$) ; 1.7 \%$ & 700 (300 to 1300$) ; 1.2 \%$ & 600 (300 to 1100$) ; 1.0 \%$ & 500 (200 to 900); $0.8 \%$ \\
\hline 5 & 64000 & 3300 (1400 to 5600); $5.2 \%$ & 1600 (700 to 2800$) ; 2.5 \%$ & 1300 (600 to 2300 ); $2.0 \%$ & 800 (300 to 1400 ); $1.3 \%$ & 700 (300 to 1300$) ; 1.1 \%$ \\
\hline Total & 273000 & 7200 (3200 to 12500 ); $2.6 \%$ & 3500 (1500 to 6200$) ; 1.3 \%$ & 2600 (1200 to 4600$) ; 1.0 \%$ & 2200 (1000 to 3800$) ; 0.8 \%$ & 1800 (700 to 3400$) ; 0.7 \%$ \\
\hline $\begin{array}{l}\text { Absolute } \\
\text { inequality }\end{array}$ & 20400 & 3000 (1300 to 5200); $14.7 \%$ & 1500 (600 to 2600$) ; 7.4 \%$ & 1200 (600 to 2200 ); $5.9 \%$ & 700 (200 to 1200 ); $3.4 \%$ & 600 (300 to 1100$) ; 2.9 \%$ \\
\hline
\end{tabular}




\begin{tabular}{|c|c|c|c|c|c|}
\hline$I M D Q$ & Total ban & Label (no SEC gradient) & Fast food & Label (SEC gradient) & Restaurant \\
\hline 1 & $200(100$ to 400$)$ & 100 (0 to 200) & $100(0$ to 100$)$ & 100 (0 to 200) & $100(0$ to 200$)$ \\
\hline 2 & 600 (200 to 1000) & 300 (100 to 500) & 200 (100 to 300$)$ & 200 (100 to 400) & 200 (100 to 400$)$ \\
\hline 3 & 1000 (400 to 1800) & 500 (200 to 900$)$ & 300 (100 to 600$)$ & 400 (100 to 700$)$ & 300 (100 to 600$)$ \\
\hline 4 & 2200 (800 to 3900) & 1100 (400 to 2000) & 800 (300 to 1400$)$ & 700 (200 to 1200) & 600 (200 to 1100$)$ \\
\hline 5 & 3900 (1500 to 6800) & 2000 (700 to 3500$)$ & 1600 (600 to 2800$)$ & 1000 (300 to 1700) & 900 (300 to 1600) \\
\hline Total & 7900 (3000 to 13900$)$ & 4000 (1400 to 7100$)$ & 3000 (1100 to 5200) & 2400 (700 to 4200$)$ & 2100 (700 to 3900$)$ \\
\hline
\end{tabular}

7200 fewer deaths (95\% confidence interval 3200 to 12500). Absolute inequality in mortality from coronary heart disease might be reduced more substantially, by nearly $15 \%$, representing almost 3000 fewer deaths (1300 to 5200). The other modelled policies might reduce the number of deaths by 1800 to 3500, thus being at most half as effective as the total ban. The reduction in absolute inequality of deaths from coronary heart disease would similarly be at most half as much, with a reduction in the range of 600 to 1500 . Labelling with no socioeconomic gradient would be the most effective policy after the total ban, followed by the fast food ban. Reduction in trans fatty acids is thus key to reducing inequality in mortality from coronary heart disease because more disadvantaged individuals have higher consumption ${ }^{16}$ and higher mortality from coronary heart disease. ${ }^{2}$

If reformulation costs to industry occur as part of the regular business cycle, any policy we modelled would be dominant over a "do nothing" scenario, where consumption of trans fatty acids remains constant, even when we consider uncertainty in the estimates. If reformulation costs to industry are substantial, these policy options would still be dominant over a "do nothing" scenario based on the best estimates, though the uncertainty leaves some possibility of net losses in the short term horizon that we focused on.

The policies we modelled vary in their assumed coverage: ${ }^{43} 100 \%$ coverage for a total ban, at most $49 \%$ for labelling, and at best $40 \%$ for a restaurant/fast food ban. There would likely be socioeconomic gradients in response to labelling and place specific bans, further reducing the coverage among the most disadvantaged groups. By failing to reach those individuals who stand to benefit most, these policies might be only a third to a half as effective.

Public health policies vary in whether they change the environment (structural policies) or rely on individual behaviour change (agentic policies). ${ }^{44}$ Agentic policies generally widen health inequalities, whereas structural policies can reduce inequalities or be neutral. ${ }^{4546}$ The policies we modelled are all structural in the sense that they would change the food environment to restrict consumption of trans fatty acids. The reduction in coverage among the most disadvantaged stems from an agentic element to labelling and restaurant

\begin{tabular}{|c|c|c|c|c|c|}
\hline IMDQ & Total ban & $\begin{array}{l}\text { Label (no SEC } \\
\text { gradient) }\end{array}$ & Fast food & Label (SEC gradient) & Restaurant \\
\hline \multicolumn{6}{|c|}{ Healthcare savings (2015-2020) } \\
\hline 1 & $1.6(0.7$ to 2.5$)$ & $0.8(0.3$ to 1.2$)$ & $0.4(0.2$ to 0.6$)$ & $0.8(0.3$ to 1.2$)$ & $0.6(0.3$ to 1.0$)$ \\
\hline 2 & 3.7 (1.6 to 5.7$)$ & $1.8(0.8$ to 2.8$)$ & $1.0(0.4$ to 1.5$)$ & $1.6(0.7$ to 2.5$)$ & $1.3(0.6$ to 2.0$)$ \\
\hline 3 & $5.9(2.6$ to 9.3$)$ & $2.9(1.3$ to 4.6$)$ & 1.9 (0.8 to 3.0$)$ & $2.2(1.0$ to 3.4$)$ & 1.9 (0.8 to 3.0$)$ \\
\hline 4 & $11.6(5.1$ to 18.2$)$ & $5.8(2.5$ to 9.0$)$ & $4.1(1.8$ to 6.4$)$ & $3.6(1.6$ to 5.7$)$ & 3.1 (1.4 to 4.9$)$ \\
\hline 5 & 19.2 (8.4 to 30.1$)$ & 9.6 (4.2 to 15.0$)$ & 7.9 (3.5 to 12.3$)$ & $4.8(2.1$ to 7.6$)$ & $4.4(1.9$ to 6.9$)$ \\
\hline Total & $41.9(18.5$ to 65.8$)$ & $20.8(9.2$ to 32.7$)$ & $15.2(6.7$ to 23.8$)$ & $13.0(5.7$ to 20.4$)$ & $11.3(5.0$ to 17.8$)$ \\
\hline \multicolumn{6}{|c|}{ Averted productivity loss (2015-20) } \\
\hline 1 & $1.8(0.8$ to 2.8$)$ & 0.9 (0.4 to 1.4$)$ & $0.4(0.2$ to 0.6$)$ & $0.9(0.4$ to 1.4$)$ & $0.7(0.3$ to 1.1$)$ \\
\hline 2 & 4.3 (1.9 to 6.7$)$ & 2.1 (0.9 to 3.3) & $1.1(0.5$ to 1.8$)$ & 1.9 (0.8 to 2.9$)$ & 1.5 (0.7 to 2.3$)$ \\
\hline 3 & 7.4 (3.3 to 11.6$)$ & $3.7(1.6$ to 5.7$)$ & 2.4 (1.1 to 3.8$)$ & $2.7(1.2$ to 4.3$)$ & 2.4 (1.1 to 3.8$)$ \\
\hline 4 & $15.8(7.0$ to 24.9$)$ & $7.9(3.5$ to 12.4$)$ & $5.6(2.4$ to 8.7$)$ & $5.0(2.2$ to 7.8$)$ & $4.3(1.9$ to 6.7$)$ \\
\hline 5 & $29.8(13.1$ to 46.7$)$ & $14.9(6.6$ to 23.4$)$ & $12.3(5.4$ to 19.3$)$ & 7.5 (3.3 to 11.8$)$ & 6.9 (3.0 to 10.8) \\
\hline Total & 59.1 (26.0 to 92.7$)$ & $29.4(13.0$ to 46.2$)$ & 21.8 (9.6 to 34.2$)$ & $18.0(7.9$ to 28.2$)$ & $15.8(6.9$ to 24.8$)$ \\
\hline \multicolumn{6}{|c|}{ Informal care savings (2015-20) } \\
\hline 1 & $7.3(3.2$ to 11.4$)$ & $3.6(1.6$ to 5.6$)$ & $1.6(0.7$ to 2.6$)$ & $3.6(1.6$ to 5.6$)$ & $2.9(1.3$ to 4.6$)$ \\
\hline 2 & 17.0 (7.5 to 26.7$)$ & $8.4(3.7$ to 13.1$)$ & $4.5(2.0$ to 7.1$)$ & $7.3(3.2$ to 11.5$)$ & 5.9 (2.6 to 9.2$)$ \\
\hline 3 & $27.5(12.1$ to 43.3$)$ & $13.6(6.0$ to 21.3$)$ & 8.9 (3.9 to 14.0$)$ & $10.2(4.5$ to 16.0$)$ & 8.9 (3.9 to 14.0$)$ \\
\hline 4 & $54.2(23.9$ to 85.1$)$ & 26.9 (11.8 to 42.2$)$ & 18.9 (8.3 to 29.7$)$ & 16.9 (7.4 to 26.5$)$ & 14.5 (6.4 to 22.8$)$ \\
\hline 5 & 89.7 (39.5 to 140.8$)$ & 44.7 (19.7 to 70.2$)$ & 36.8 (16.2 to 57.7$)$ & 22.6 (9.9 to 35.4$)$ & 20.6 (9.1 to 32.3) \\
\hline Total & 195.7 (86.1 to 307.3) & 97.1 (42.7 to 152.5$)$ & 70.8 (31.1 to 111.1) & 60.5 (26.6 to 95.0$)$ & 52.9 (23.3 to 83.0) \\
\hline Grand total & 296.7 (130.6 to 465.9) & 147.4 (64.9 to 231.4$)$ & 107.7 (47.4 to 169.1$)$ & $91.5(40.2$ to 143.6$)$ & $80.0(35.2$ to 125.6$)$ \\
\hline
\end{tabular}




\begin{tabular}{|c|c|c|c|c|c|c|}
\hline & \multirow{2}{*}{$\begin{array}{l}\text { Common to } \\
\text { all policies }\end{array}$} & \multicolumn{5}{|c|}{ Industry costs (worst case) } \\
\hline & & Total ban & Label (no SEC gradient) & Fast food & Label (SEC gradient) & Restaurant \\
\hline \multicolumn{7}{|l|}{ Government: } \\
\hline Legislation & 5.0 & - & - & - & - & - \\
\hline Monitoring & 16.6 & - & - & - & - & - \\
\hline \multicolumn{7}{|l|}{ Industry: } \\
\hline Ongoing expenses & 11.0 & - & - & - & - & - \\
\hline Reformulation & & 200.0 & 92.9 & 62.6 & 56.1 & 47.4 \\
\hline Sum all costs & 32.6 & 232.6 & 125.5 & 95.2 & 88.7 & 80.0 \\
\hline Sum all savings & - & 296.7 (130.6 to 465.9) & $147.4(64.9$ to 231.4$)$ & 107.7 (47.4 to 169.1) & $91.5(40.2$ to 143.6$)$ & $80.0(35.2$ to 125.6$)$ \\
\hline Optimistic net cost & - & $-264.1(-433.3$ to -98.0$)$ & $-114.8(-198.8$ to -32.2$)$ & $-75.1(-136.5$ to -14.8$)$ & $-58.9(-111.0$ to -7.6$)$ & $-47.4(-93.0$ to -2.6$)$ \\
\hline Pessimistic net cost & - & $-64.1(-233.3$ to 102.0$)$ & $-21.9(-105.9$ to 60.6$)$ & $-12.5(-73.9$ to 47.8$)$ & $-2.8(-54.9$ to 48.4$)$ & $0.0(-45.5$ to 44.8$)$ \\
\hline
\end{tabular}

bans. We did not model any purely agentic policies because there is little evidence of their effectiveness in dissuading people from consuming products with trans fatty acids. Our results are also consistent with the idea that structural interventions need to be inter-sector in nature, not just relying on healthcare to reach vulnerable populations. ${ }^{47}$

Recent downward trends in consumption of trans fatty acids in the $\mathrm{UK}^{48}$ are a result of voluntary reformulation of some products (such as biscuits/cookies). ${ }^{49}$ Complete elimination in countries such as Denmark, however, shows that continued reformulation is technically feasible. ${ }^{919}$ In fact Denmark showed the largest decline in mortality from coronary heart disease in the EU from 1980 to 2009, but the precise contribution of the ban to this trend has not been quantified. ${ }^{50}$ Furthermore, lowering average consumption with less stringent policies might still conceal small groups of consumers with extremely high consumption. In Denmark before the ban, an estimated $1 \%$ of the population were consuming around $5 \mathrm{~g} /$ day of trans fatty acids, with potentially large mortality consequences. ${ }^{51}$

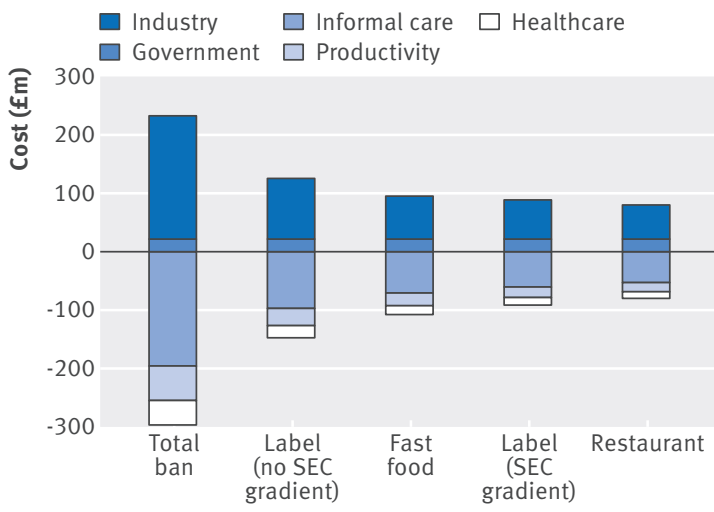

Fig 1 | Contributions of each cost category for each policy option for reduction in trans fatty acids. Costs to government and industry are expressed as positive and savings from reductions in direct healthcare, productivity loss, and informal care are expressed as negative.

(Confidence intervals on savings are shown in table 6; net costs are shown in table 7 and fig 2 )

\section{Strengths and limitations}

We used data from a meta-analysis directly linking consumption of trans fatty acids to incidence of coronary heart disease. This removes uncertainty that would accompany modelling a link mediated by cholesterol, and it therefore also includes non-cholesterol effects associated with inflammation. The effects should be even greater if trans fatty acids are replaced withcis unsaturated fats. ${ }^{4}$ Generally, foods can be reformulated to remove trans fatty acids without substantially increasing saturated fats, ${ }^{925}$ though this might vary by product type. 4952

There is debate about whether ruminant trans fatty acids are harmful. While there are no proved links between consumption of ruminant trans fatty acids and mortality from coronary heart disease,,$^{53}$ ruminant trans fatty acids increases cholesterol concentration, as does industrial trans fatty acids. ${ }^{54}$ Additional health gains and cost savings might be possible by shifting to a plant

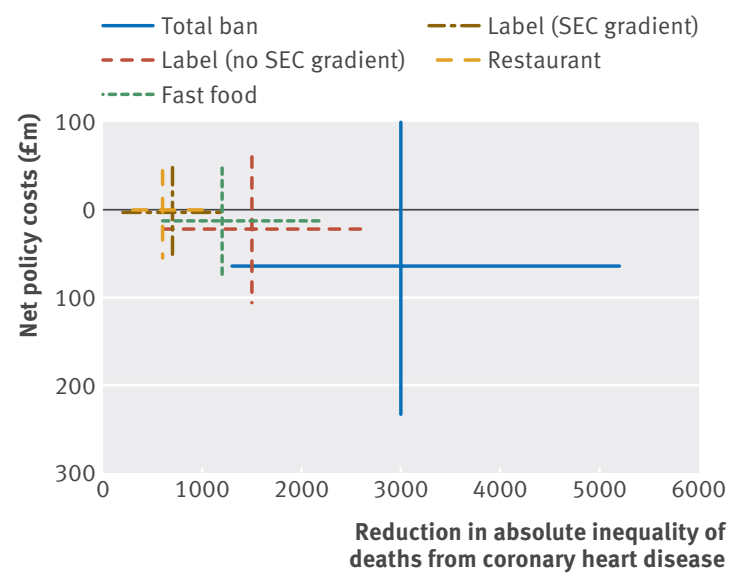

Fig $2 \mid$ Net costs (negative is saving) versus reduction in inequality of coronary heart disease mortality (positive is reduction). Net costs are from pessimistic scenario (table 7), where industry reformulation costs are substantial. Reduction in absolute inequalities is change in slope index with and without each policy option. Total ban separates from other policy options along both cost effectiveness and inequality reduction axes. In fig $B$ in the appendix, the optimistic scenario is presented, which excludes reformulation costs to industry 
based diet, but we did not model this because we focus on trans fatty acids in processed foods.

Our health outcomes analysis assumes continuing declines in incidence of and mortality from coronary heart disease. If future mortality in England plateaus or increases, elimination of trans fatty acids could have even greater benefits. In the case of mortality, the declines are likely to be rapid enough to counteract population ageing. ${ }^{55}$ We assumed that mortality would decline in the same proportion as incidence, rather than additionally modelling changes in case fatality rates. Declines in mortality from coronary heart disease have been shown to depend more on incidence than on case fatality. ${ }^{56}$

We used an area based measure of socioeconomic status (IMDQ). Within an area there will naturally be mixing of individuals with higher and lower status. Therefore, we cannot make firm conclusions about individuals. The advantage of IMDQ is that it allows us to model coronary heart disease mortality for the whole of England without the need to infer from a sample. Further, the dietary surveys we used ${ }^{15} 16$ are the most detailed source of consumption of trans fatty acids for our population. Other sources report higher total food energy intake ${ }^{57}$ but do not indicate the consumption of trans fatty acids. As the effect of trans fatty acids operates on a percentage basis (food energy from trans fatty acids divided by total food energy), differences between surveys would affect the results only if consumption were substantially misreported in the surveys we used.

\section{Conclusions}

Elimination of trans fatty acids from processed foods is an achievable target for public health policy. Dietary changes can have a rapid effect on coronary heart disease. ${ }^{5859}$ A total ban on trans fatty acids in England is technically feasible and one that neighbouring countries have already accomplished. ${ }^{91960}$ Such a ban would lead to health benefits at least twice as large as other policy options, both in terms of total population benefit and reduction in inequality. Continuing to rely on industry cooperation via the responsibility deal might be insufficient. Furthermore, if attention shifts away from trans fatty acids, these toxic substances could creep back into processed foods. The current policy climate is ideal for shutting the door effectively on trans fatty acids. Decisive action is now indicated, prioritising the most effective and cost effective policy options.

We thank Marissa Collins and Helen Mason of Yunus Centre for Social Business and Health for providing economic data. We also acknowledge the development of the original IMPACT SEC model. The English SEC project was conducted by M Bajekal and S Scholes. H Hande set up the worksheet template; S Scholes populated the model and was its custodian; M Bajekal ensured the integrity of inputs and outputs and provided SEC related methodological solutions. M O'Flaherty and N Hawkins provided support, clinical expertise, and generated the therapeutic input. The UCL team was led by R Raine, and S Capewell coordinated the overall project.

Contributions: MOF and SC developed the idea. KA and JP designed the analysis. All authors commented on versions of the manuscript for key intellectual content. KA is guarantor.

Funding: This article presents independent research funded by the National Institute for Health Research's School for Public Health
Research (NIHR SPHR). The SPHR is funded by the National Institute for Health Research (NIHR). SPHR is a partnership between the Universities of Sheffield, Bristol, Cambridge, Exeter, UCL; London School for Hygiene and Tropical Medicine; LiLaC collaboration between the Universities of Liverpool and Lancaster and Fuse; Centre for Translational Research in Public Health, a collaboration between Newcastle, Durham, Northumbria, Sunderland, and Teesside Universities. The views expressed are those of the author(s) and not necessarily those of the NHS, the NIHR, or the Department of Health. The funders had no role in study design, data collection and analysis, decision to publish, or preparation of the manuscript.

Competing interests: All authors have completed the ICMJE uniform disclosure form atwww.icmje.org/coi_disclosure.pdf (available on request from the corresponding author) and declare: no support from any organisation for the submitted work; no financial relationships with any organisations that might have an interest in the submitted work in the previous three years; no other relationships or activities that could appear to have influenced the submitted work.

Ethical approval: Not required.

Transparency: The lead author affirms that the manuscript is an honest, accurate, and transparent account of the study being reported; that no important aspects of the study have been omitted; and that any discrepancies from the study as planned have been explained.

Data sharing: Input data for the model are available from corresponding author on request.

This is an Open Access article distributed in accordance with the terms of the Creative Commons Attribution (CC BY 4.0) license, which permits others to distribute, remix, adapt and build upon this work, for commercial use, provided the original work is properly cited. See:http://creativecommons.org/licenses/by/4.0/.

1 Townsend N, Wickramasinghe K, Bhatnagar P, et al. Coronary heart disease statistics. British Heart Foundation, 2012.

2 Bajekal M, Scholes S, O'Flaherty M, Raine R, Norman P, Capewell S. Unequal trends in coronary heart disease mortality by socioeconomic circumstances, England 1982-2006: an analytical study. PLOS ONE 2013;8:e59608

3 Allen K, Gillespie DO, Guzman Castillo M, Diggle PJ, Capewell S, O'Flaherty M. Predicting future trends and inequalities in premature coronary heart disease deaths in England: modelling study. IEpidemiol Community Health 2014;68(suppl 1):A35.

4 Mozaffarian D, Katan MB, Ascherio A, Stampfer MJ, Willett WC. Trans fatty acids and cardiovascular disease. N Engl I Med 2006;354: 1601-13.

5 Kiage JN, Merrill PD, Robinson CJ, et al. Intake of trans fat and all-cause mortality in the reasons for geographical and racial differences in stroke (REGARDS) cohort. Am J Clin Nutr 2013;97:1121-8.

6 O'Flaherty M, Flores-Mateo G, Nnoaham M, Lloyd-Williams F, Capewell S. Potential cardiovascular mortality reductions with stricter food policies in the United Kingdom of Great Britain and Northern Ireland. Bull World Health Organ 2012.90:522-31.

7 UK Faculty of Public Health/Royal Society for Public Health. 12 steps to better public health: a manifesto. www.fphm.org.uk/resources/ AtoZ/manifesto/manifesto.pdf.

8 WHO. Global strategy on diet, physical activity and health. WHO, 2004

9 Department of Health. Revisions to artificial trans fats removal pledge DoH, 2012. https://responsibilitydeal.dh.gov.uk/ revisions-to-artificial-trans-fats-removal-pledge/

10 Downs SM, Thow AM, Leeder SR. The effectiveness of policies for reducing dietary trans fat: a systematic review of the evidence. Bull World Health Organ 2013;91:262-9H.

11 Bajekal M, Scholes S, Love H, et al. Analysing recent socioeconomic trends in coronary heart disease mortality in England, 2000-2007: a population modelling study. PLoS Med 2012;9:e1001237.

12 Pearson-Stuttard J, Critchley J, Capewell S, et al. Quantifying the socio-economic benefits of reducing industrial dietary trans fats: modelling study. PLOS ONE 2015:10:e0132524.

13 O'Keeffe C, Kabir Z, O'Flaherty M, et al. Modelling the impact of specific food policy options on coronary heart disease and stroke deaths in Ireland. BMJ Open 2013:3:e002837.

14 Department for Communities and Local Government. English indices of deprivation 2010. www.gov.uk/government/uploads/system/ uploads/attachment data/file/6222/1871538.pdf

15 Public Health England. National diet and nutrition survey results from years 1, 2, 3 and 4 (combined) of the rolling programme (2008/20092011/2012). Food Standards Agency, 2014.

16 Food Standards Agency. Low income diet and nutrition survey. 2007.www.food.gov.uk/science/dietarysurveys/lidnsbranch/.

17 Leth T, Jensen HG, Mikkelsen AÆ, Bysted A. The effect of the regulation on trans fatty acid content in Danish food. Atherosclerosis Supplements 2006:7:53-6. 
18 Stender S, Astrup A, Dyerberg J. Ruminant and industrially produced trans fatty acids: health aspects. Food Nutr Res 2008;52:10.3402/fnr. v52i0.1651.

19 Coombs R. Trans fats: chasing a global ban. BMJ 2011;343:d5567.

20 World Cancer Research Fund International. Improve food supply. 2015. http://www.wcrf.org/int/policy/nourishing-framework/ improve-food-supply.

21 Food and Drug Administration. Tentative determination regarding partially hydrogenated oils. Fed Regist 2013;78:67169-75.

22 Clapp J, Curtis C), Middleton AE, Goldstein GP. Prevalence of partially hydrogenated oils in US packaged foods, 2012. Prev Chronic Dis 2014;11:e145.

23 Otite F, Jacobson MF, Dahmubed A, Mozaffarian D. Trends in trans fatty acids reformulations of US supermarket and brand-name foods from 2007 through 2011. Prev Chronic Dis 2013;10:E85

24 Gillespie DOS, Allen K, Guzman-Castillo M, et al. The health equity and effectiveness of policy options to reduce dietary salt intake in England: policy forecast. PLOS ONE 2015;10:e0134064

25 Angell SY, Cobb LK, Curtis CJ, Konty KJ, Silver LD. Change in trans fatty acid content of fast-food purchases associated with New York City's restaurant regulation: a pre-post study. Ann Intern Med 2012;157:81-6.

26 Office of National Statistics. Family spending. ONS, 2012. www.ons. gov.uk/ons/rel/family-spending/family-spending/family-spending2012-edition/index.html.

27 Prospective Studies Collaboration, Lewington S, Whitlock G, et al. Blood cholesterol and vascular mortality by age, sex, and blood pressure: a meta-analysis of individual data from 61 prospective studies with 55000 vascular deaths. Lancet 2007;370:1829-39.

28 Smolina K, Wright L, Rayner M, Goldacre MJ. Long-term survival and recurrence after acute myocardial infarction in England, 2004 to 2010. Circ Cardiovasc Qual Outcomes 2012:5:532-40.

29 Office of National Statistics. Inequality in disability-free life expectancy by area deprivation: England, 2003-06 and 2007-10. ONS, 2013 http://www.ons.gov.uk/ons/dcp171778 319481.pdf.

30 Hawkins N, Scholes S, Bajekal M, et al. The UK National Health Service: delivering equitable treatment across the spectrum of coronary disease. Circ Cardiovasc Qual Outcomes 2013;6:208-16.

31 NICE. Cost-effectiveness analysis-pharmacological treatment. NICE, 2011. https://www.nice.org.uk/guidance/cg127/resources/ cg127-hypertension-full-guideline-appendix-i-costeffectivenessanalysis-pharmacological-treatment2.

32 World Health Organization. Handbook on health inequality monitoring. WHO, 2013. http://www.who.int/gho/health_equity/ handbook/en/.

33 Collins M, Mason H, O’Flaherty M, Guzman-Castillo M, Critchley J, Capewell S. An economic evaluation of salt reduction policies to reduce coronary heart disease in England: a policy modeling study. Value Health 2014:17:517-24.

34 Food Standards Agency. National diet and nutrition survey rolling programme: progress report. 2006. http://www.food.gov.uk/ multimedia/pdfs/pro061201.pdf.

35 British Retail Consortium. Annex 1. http://www.food.gov.uk/sites/ default/files/multimedia/pdfs/annex1parasreleasedmay09.pdf.

36 Food Standard Agency. Regulatory impact assessment: setting targets for salt levels in a range of processed foods. 2006. http://tna. europarchive.org/20130129064400/http://www.food.gov.uk/ multimedia/pdfs/salttargetsria.pdf.

37 Personal Social Services Research Unit. Unit costs of health and social care 2011. PSSU, 2011. www.pssru.ac.uk/project-pages/unit-costs/2011/.

38 Luengo-Fernández R, Leal J, Gray A, Petersen S, Rayner M. Cost of cardiovascular diseases in the United Kingdom. Heart 2006;92:1384-9.

39 Koopmanschap MA, Van Ineveld BM. Towards a new approach for estimating indirect costs of disease. Soc Sci Med 1992:34:1005-10.
40 Office for National Statistics. Consumer price inflation, September 2014. ONS, 2014. http://www.ons.gov.uk/ons/rel/cpi/consumerprice-indices/september-2014/stb---consumer-price-indices--september-2014.html.

41 R Core Team. R: a language and environment for statistical computing. R Foundation for Statistical Computing, 2014. http://www.R-project.org/.

42 Clark CE. The PERT model for the distribution of an activity time. Oper Res 1962;10:405-6.

43 Tugwell P, de Savigny D, Hawker G, Robinson V. Applying clinical epidemiological methods to health equity: the equity effectiveness loop. BMJ 2006;332:358-61.

44 McLaren L, McIntyre L, Kirkpatrick S. Rose's population strategy of prevention need not increase social inequalities in health. Int J Epidemiol 2010;39:372-7.

45 Capewell S, Graham H. Will cardiovascular disease prevention widen health inequalities? PLoS Med 2010;7:e1000320.

46 McGill R, Anwar E, Orton L, et al. Are interventions to promote healthy eating equally effective for all? Systematic review of socioeconomic inequalities in impact. BMC Public Health 2015;15:457.

47 Frolich KL, Potvin L. The inequality paradox: the population approach and vulnerable populations. Am J Public Health 2008;98:216-21.

48 Pot GK, Prynne CJ, Roberts C, et al. National diet and nutrition survey: fat and fatty acid intake from the first year of the rolling programme and comparison with previous surveys. Br J Nutr 2012;107:405-15.

49 Stender S, Astrup A, Dyerberg J. What went in when trans went out? N Engl J Med 2009;361:314-6.

50 Nichols M, Townsend N, Scarborough P, Rayner M. Trends in age-specific coronary heart disease mortality in the European Union over three decades: 1980-2009. Eur Heart J 2013;34:3017-27.

51 Stender S, Astrup A, Dyerberg J. Tracing artificial trans fat in popular foods in Europe: a market basket investigation. BMJ Open 2014; 4:e005218

52 L’Abbé MR, Stender S, Skeaff CM, Ghafoorunissa, Tavella M. Approaches to removing trans fats from the food supply in industrialized and developing countries. Eur J Clin Nutr 2009;63:S50-67.

53 Gebauer SK, Chardigny J-M, Jakobson MU, et al. Effects of ruminant trans fatty acids on cardiovascular disease and cancer: a comprehensive review of epidemiological, clinical, and mechanistic studies. Adv Nutr 2011;2:332-54

54 Brouwer IA, Wanders AJ, Katan MB. Trans fatty acids and cardiovascular health: research completed? Eur / Clin Nut 2013;67:541-7.

55 Guzman-Castillo M, Gillespie DOS, Allen K, et al. Future declines of coronary heart disease mortality in England and Wales could counter the burden of population ageing. PLoS ONE 2104;9: e99482.

56 Tunstall-Pedoe H, Vanuzzo D, Hobbs M, et al. Estimation of contribution of changes in coronary care to improving survival, event rates, and coronary heart disease mortality across the WHO MONICA Project populations. Lancet 2000;355:688-700.

57 Department for Environment, Food and Rural Affairs. Family Food 2013. DEFRA, 2014. https://www.gov.uk/government/uploads/ system/uploads/attachment_data/file/385694/familyfood2013report-11dec14.pdf.

58 Capewell S, O’Flaherty M. Rapid mortality falls after risk-factor changes in populations. Lancet 2011;378:752-3.

59 Capewell S, O'Flaherty M. Can dietary changes rapidly decrease cardiovascular mortality rates? Eur Heart / 2011;32:1187-9.

60 Stender S, Dyerberg J, Astrup A. Consumer protection through legislative ban on industrially produced trans fatty acids in foods in Denmark. Scand J Food Nutr 2006;50:155-60.

(C) BMJ Publishing Group Ltd 2015

Appendix: Supplementary information 